\title{
ESPECTROSCOPIA FOTOACÚSTICA PARA ANALISAR A FERTILIDADE DE SOLOS TRATADOS COM BIOCHAR E MICORRIZA
}

\author{
Ellen Conceição T. de Matos ${ }^{\mathrm{a}}$, Luciana A. Rodrigues ${ }^{\mathrm{b}}$, Pamella de A. Souza ${ }^{\mathrm{a}}$, Renato V. da Silva ${ }^{\mathrm{b}}$ e Roberto T. Faria Jr.,* \\ ${ }^{a}$ Centro de Ciência e Tecnologia, Universidade Estadual do Norte Fluminense Darcy Ribeiro, Av. Alberto Lamego 2000, 28013-602 \\ Campos dos Goytacazes - RJ, Brasil \\ ${ }^{\mathrm{b}}$ Centro de Ciencias e Tecnologias Agropecuárias, Universidade Estadual do Norte Fluminense Darcy Ribeiro, Av. Alberto Lamego \\ 2000, 28013-602 Campos dos Goytacazes - RJ, Brasil
}

Recebido em 27/03/2018; aceito em 16/07/2018; publicado na web em 14/08/2018

\begin{abstract}
PHOTOACOUSTIC SPECTROSCOPY TO ANALYZE THE SOIL FERTILITY TREATED WITH BIOCHAR AND MICORRIZA. For proper plant growth, soil substrates must be successful for chemical and physical properties in a way that ensures a high capability to reach the nutritional demand of the plant. A suitable nutritional method is the application of organic compounds, urea and, recently, biochar. Here, using the photoacoustic absorption spectroscopy in the visible range, it was analyzed the nutritional capacity of soil samples, submitted to different treatments. This analysis was carried out through the absorption peaks of A and B chlorophylls and cuticle of papaya leaves planted in soils with addition of biochar and with (without) mycorrhiza. All treated samples showed an increase in the peaks of chlorophyll activity in relation to the base sample. Moreover, the samples containing both mycorrhiza and biochar presented the highest peaks of chlorophyll activity, proving to be the best soil fertilization treatment.
\end{abstract}

Keywords: photoacoustic technique; soil characterization; biochar; mycorrhiza.

\section{INTRODUÇÃO}

O solo exerce grande influência sobre os ambientes e as sociedades de maneira geral, sendo ele um dos mais importantes recursos naturais, essenciais para o desenvolvimento do país. Sua formação está intimamente ligada à ação de fatores climáticos e biológicos. Em uma boa formação no solo, os substratos devem apresentar propriedades químicas e físico-hídricas tal que haja uma retenção adequada de água, para que o processo germinativo ocorra da melhor maneira possível e garanta uma alta capacidade de suprir a demanda nutricional da planta durante seu desenvolvimento. ${ }^{1}$

Sabe-se que a Amazônia apresenta, em sua grande extensão territorial, um solo pobre em relação à parte nutricional. Entretanto, em determinados pontos, é possível identificar um tipo de solo altamente fértil, chamado terra preta de índio. Este solo contém uma grande quantidade de micro cerâmicas fossilizadas incorporadas nos horizontes da superfície, oriundas, possivelmente, de urnas e utensílios cerâmicos usados pelos índios há sete mil anos atrás. ${ }^{2}$ Devido a essas excelentes características de fertilidade, pesquisadores vêm procurando métodos para reprodução de solos com um perfil semelhante. Portanto, vem sendo estudada a aplicação de biochar como uma estratégia orientada para a gestão da biota e da fertilidade do solo. Este condicionador de solos é produzido a partir da queima de biomassa e de resíduos vegetal ou animal. Por ser um condicionador mais recalcitrante, o biochar pode ser adequado quando combinado com a aplicação de compostos orgânicos, bem como associado a microrganismos do solo podendo contribuir significativamente para a melhoria das características físicas, químicas e biológicas do sistema.

Assim, foi proposto um experimento com o objetivo de avaliar o efeito do biochar, de fungos micorrizicos (FMA) e micorrizas associadas ao biochar sobre a nutrição nitrogenada e a taxa fotossintética de plantas de mamão por meio da espectroscopia fotoacústica.

A espectroscopia fotoacústica de absorção na faixa do espectro eletromagnético visível é uma técnica alternativa aos métodos

*e-mail: rfaria@uenf.br convencionais. Esta técnica consiste em medir o calor e o oxigênio liberados pela incidência de luz sobre a folha de uma planta. O processo fotossintético inicia com a absorção de energia, proveniente da luz. A energia absorvida excita e libera elétrons das moléculas de clorofila, dando início à fase fotoquímica da fotossíntese. Nesta fase é gerado o oxigênio e o armazenamento de energia, no entanto, nem toda a energia absorvida é armazenada, parte dela se dissipa em forma de calor, que pela técnica, é convertida em sinal elétrico, chamado de sinal fotoacústico. A técnica fotoacústica vem sendo muito utilizada por não necessitar de grande preparação da amostra, podendo ser utilizada "in vivo"33 e, também, por possibilitar uma determinação mais rápida dos picos das clorofilas nas folhas, em detrimento das técnicas convencionais.

\section{Biochar}

A história do biochar começa com a descoberta da chamada "Terra Preta de Índio", levando à realização de estudos em solos antropogênicos na Amazônia. ${ }^{4} \mathrm{O}$ biochar é um material sólido obtido da conversão termoquímica de biomassa em um ambiente com ausência ou pouca presença de oxigênio (pirólise). A pirólise permite a fixação de $20 \%$ a $50 \%$ do carbono presente da biomassa. A composição do biocarvão pode ser grosseiramente dividida em carbono recalcitrante, instável ou lixiviável e cinzas. A maior diferença química entre o biocarvão e o carvão vegetal é a proporção de cadeias aromáticas de carbono em suas estruturas, que é maior no biocarvão. ${ }^{5}$

Praticamente, qualquer tipo de biomassa atende à produção do biochar. Porém, devido às diferenças existentes na composição química e na estrutura física e molecular desses materiais, assim como nas condições da pirólise, o biochar obtido ao fim do processo de produção apresenta características físicas e químicas variáveis. Tais variações promovem no solo diferenças na porosidade, na superfície específica, no $\mathrm{pH}$, na capacidade de troca iônica, recalcitrância, etc. ${ }^{6}$ Essas diferenças refletem nas respostas agronômicas e ambientais.

O biochar apresenta capacidade na retenção de água e de elementos químicos provenientes de adubos orgânicosou minerais, 
devido à abundância em sua estrutura de micro poros. Estes minerais retidos pelo biochar ligam-se aos grupos carboxílicos e fenólicos carregados negativamente. Tal retenção diminui a lixiviação e melhora a eficiência da adubação, ${ }^{7}$ por isso é indicado o seu uso como condicionador do solo.

A adição deste condicionador de solo influencia diretamente na resposta do solo, não só na adição de água, como também na sua agregação, aeração, elasticidade e na capacidade de retenção de cátions.

Solos arenosos apresentam baixa microporosidade. A microporosidade é importante na retenção de água e partículas com baixa superfície específica, o que reduz a capacidade do solo de reter os nutrientes por ligações eletrostáticas, como é comum ocorrer nos solos argilosos. Como o biochar tem o poder de reter líquidos e nutrientes em seus microporos, tem, assim, a capacidade demelhorar as características químicas de solos arenosos pelo aumento na quantidade de cargas ativas, possibilitando melhorias semelhantes àquelas dos solos argilosos. ${ }^{8}$

\section{Micorriza}

A micorriza é um fungo que tem um papel importante na sobrevivência e no crescimento das plantas principalmente nos trópicos, onde predomina em solos de baixa fertilidade, carentes em fósforo disponível. ${ }^{9}$ A propagação desses fungos ocorre através de esporos, do micélio e de fragmentos de raízes colonizadas coletivamente, denominadas propágulos que, ao infectarem as raízes da planta hospedeira, desenvolvem-se e inicia-se uma associação mutualística com estas raízes. ${ }^{10}$ São amplamente distribuídos na maioria dos ecossistemas, desde desertos até florestas, tanto em regiões tropicais e temperadas quanto em regiões árticas. Representam a mais ampla associação entre plantas e fungos encontrada na natureza. ${ }^{11} \mathrm{O}$ caráter mutualista da micorriza contribui para a evolução e a sobrevivência das plantas terrestres e dos próprios fungos que existem há 400 milhões de anos. ${ }^{12}$

As micorrizas podem amenizar as limitações causadas pelo homem ao ambiente, pois, quando associadas às raízes, aumentam a capacidade adaptativa das plantas às condições adversas, como a baixa disponibilidade de nutrientes ( $\mathrm{Ne} \mathrm{P}$ ), ao estresse hídrico, ao pH baixo, à temperatura elevada, a diminuição da atividade microbiana. ${ }^{13}$ Além disso, as micorrizas permitem a interconecção entre plantas de mesma e de diferentes espécies promovendo a transferência de nutrientes entre elas. ${ }^{14} \mathrm{Em}$ geral, plantas colonizadas por micorrizas eficientes são mais competitivas e têm maior capacidade de sobrevivência em solos de baixa fertilidade. ${ }^{15}$

Diminuições observadas ocasionalmente na população de fungos micorrízicos podem ser causados pela alta disponibilidade de nutrientes no solo, assim, reduzindo a necessidade da planta pela simbiose. ${ }^{16}$ Alterações acentuadas nas condições do solo, como por exemplo, variação do $\mathrm{pH}$, salinidade ou contaminação por metais pesados, também podem alterar a colonização micorrízica. ${ }^{17} \mathrm{Com}$ isso a aplicação de condicionadores do solo, como o biocarvão, pode alterar a sobrevivência das micorrizas, a interação planta hospedeira-fungo micorrízico e as respostas da planta à inoculação. Os sistemas de poros internos das partículas de biocarvão podem proteger o micélio extra-radical de herbívoros. ${ }^{18}$ Além disso, a sorção de compostos de sinalização, desintoxicação de alelo químico, propriedades físico-químicas do solo ou efeitos indiretos através de alterações sobre outras populações microbianas do solo podem indiretamente afetar as micorrizas. ${ }^{18}$

\section{O Processo da Fotossíntese}

A energia solar é essencial para a evolução da vida na Terra. A fotossíntese é o processo através do qual as plantas, algas e certos tipos de bactérias verdes convertem energia luminosa em energia química, paraa síntese de compostos orgânicos.

Ela resulta na liberação do oxigênio, pela quebra da molécula de água, enquanto o gás carbônico é removido da atmosfera e usado na síntese de carboidratos $\left(\mathrm{C}_{\mathrm{n}} \mathrm{H}_{2 \mathrm{n}} \mathrm{O}_{\mathrm{n}}\right)$ Este processoé composto por uma cadeia de reações de óxido-redução que pode ser resumida através da Equação 1: ${ }^{19}$

$$
\mathrm{n} \mathrm{CO}_{2}+\mathrm{n} \mathrm{H}_{2} \mathrm{O}+\mathrm{Luz} \rightarrow \mathrm{C}_{\mathrm{n}} \mathrm{H}_{2 \mathrm{n}} \mathrm{O}_{\mathrm{n}}+\mathrm{n} \mathrm{O}_{2}
$$

O processo de fotossíntese pode ser dividido em duas séries de reações. A primeira depende da absorção de luz e consiste na divisão da molécula de água e na produção de oxigênio e compostos armazenadores de energia, entre eles o ATP (trifosfato de adenosina) e NADPH (Nicotinamida Adenina Dinucleótido Fosfato). Esta absorção acontece em moléculas (ou pigmentos), como as clorofilas e os carotenóides, formando o chamado "sistema de antenas", que são os centros de reação fotossintética, onde ocorrem as transferências primárias de elétrons, ou seja, excita os elétrons das moléculas de clorofila que saem da estrutura, dando início à fase fotoquímica da fotossíntese. Assim, os pigmentos fotossintetizantes absorvem a luz e impulsionam a fotossíntese..$^{20} \mathrm{As}$ distâncias entre os pigmentos e sua orientação relativa seguem um arranjo geométrico fixo que facilita a transferência da energia captada da luz e a transferência de elétrons nos centros de reação. ${ }^{21} \mathrm{Na}$ etapa seguinte, estes compostos são usados para produzir carboidratos, proteínas e lipídios a partir do gás carbônico atmosférico. ${ }^{19}$

A partir dessas discussões, será possível efetuar relações entre as características fisiológicas e os perfis da fotossíntese. Podendo se destacar que a espectroscopia fotoacústica, por ser uma técnica mais sensível do que às utilizadas na Bioquímica, deverá perceber mais rapidamenteas mudanças estruturais e morfológicas nas folhas.

Aqui, a análise da fotossíntese será utilizada para qualificar os solos tratados com combinações distintas de micorriza e/ou biochar, através de folhas de mamoeiro Golden (Carica Papaya L) cujas plantas estão acondicionadas em vasos com as amostras de solo investigadas neste trabalho.

\section{Ciência Fototérmica}

A Ciência Fototérmica é uma das ciências responsáveis pela conversão da energia de radiação eletromagnética em energia térmica. Esse fenômeno é definido por Efeito Fototérmico. ${ }^{22} \mathrm{~A}$ aplicação desta ciência pode ser realizada através das técnicas fototérmicas, normalmente utilizadas para a caracterização térmica de materiais. Elas englobam uma série de técnicas, dentre elas a Espectroscopia Fotoacústica, Lentes Térmicas, Deflexão Fototérmica, Difração Fototérmica, Radiometria Fototérmica e Espectroscopia de Interferometria Fototérmica. Isso permite uma gama de aplicações a uma série de materiais, abrangendo os três estados físicos da matéria: sólido, líquido e gasoso. Essa conversão pode estar associada a algumas particularidades do material absorvente, uma vez que tal efeito pertinente à excitação dos estados eletrônicos de átomos e/ ou moléculas gera a emissão de ondas eletromagnéticas não radiativas, sob a forma de energia/calor. A espectroscopia fototérmica é bem apropriada, por exemplo, para análises químicas que exijam ultrasensibilidade. ${ }^{23}$ Dentre as diversas técnicas compreendidas pela Ciência Fototérmica, faz-se presente a Fotoacústica, cujo fenômeno está relacionado com a absorção da radiação de uma onda eletromagnética por uma amostra e a sua conversão em uma onda acústica, devido à variação de pressão ocasionada pelo aquecimento da mesma. A energia absorvida propaga-se de maneira amortecida, sob a forma de ondas térmicas em seu interior. $\mathrm{O}$ primeiro efeito desse gênero foi observado por Alexander Graham Bell, em 1890, 
quando estudava um aparelho capaz de converter luz em som, que posteriormente foi denominado "photophone". Em seguida, Bell se dedicou a investigar os efeitos fotoacústicos em líquidos e gases. ${ }^{24}$ Com o advento do microfone, em 1938, aumentou o interesse por experimentos qualitativos e quantitativos em gases e surgiram diversas teorias a respeito. Basicamente, o aparelho inventado por Bell possuía o seguinte princípio de funcionamento: por meio de um espelho, ele focalizava os raios solares sobre uma membrana, a qual vibrava sob o efeito de sua voz. O feixe de luz modulado era direcionado a uma célula de selênio, integrada a um circuito eletrônico de um telefone, que transformava a luz em som. ${ }^{22}$

Com o aparecimento dos lasers na década de 70, houve uma expansão significativa das técnicas fototérmicas. Em 1976, surge o primeiro modelo teórico do efeito fotoacústico em sólidos, proposta por Rosencwaig e Gersho. ${ }^{24}$ Outros pesquisadores continuaram desenvolvendo modelos matemáticos para melhor entender a técnica e suas diversas formas de aplicação. Hoje a espectroscopia fotoacústica tem aplicações não apenas na Física, mas na Química, Biologia, Agronomia, Medicina e Engenharias. ${ }^{25}$

\section{Modelo RG (Rosencwaig e Gersho)}

O modelo RG baseia-se em uma luz modulada que incide na amostra em contato com uma câmara de gás (geralmente o ar) de espessura $1_{\mathrm{s}}$ e um suporte de espessura $1_{\mathrm{b}}$. A câmara de gás é fechada por uma janela de quartzo (transparente à radiação incidente) e acoplado a esta câmara há um microfone que detecta variações de pressão no gás. A Figura 1 mostra um desenho esquemático da célula fotoacústica fechada. ${ }^{24} \mathrm{~A}$ configuração unidimensional do padrão da célula fotoacústica consiste em uma amostra sólida colocada dentro de uma pequena célula cheia de gás (ar) a uma distância $1_{g}$ de uma janela de vedação transparente, pela qual incide um feixe de luz modulado. Admite-se que o gás não absorva a energia da radiação proveniente de uma fonte que passa pela janela e que atinge a amostra. Um microfone capacitivo, inserido numa das paredes laterais da célula, capta as flutuações de pressão no gás (sinal fotoacústico).

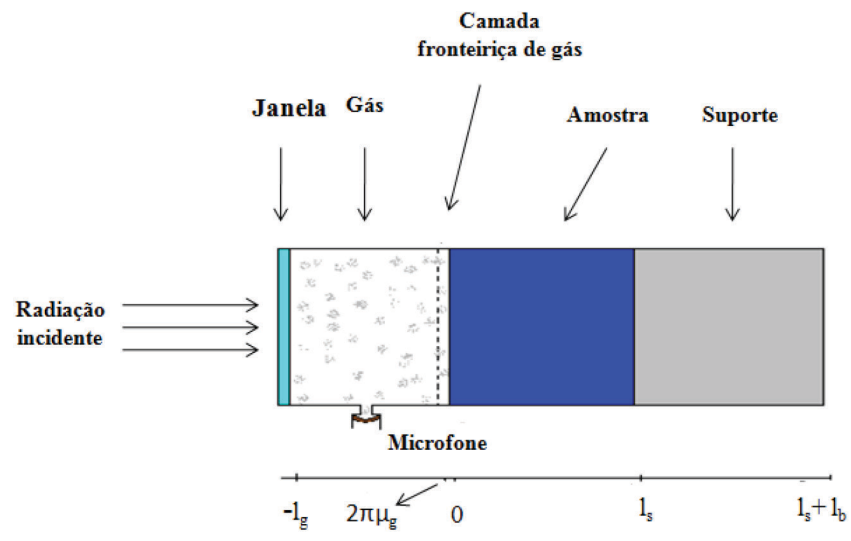

Figura 1. Esquema da célula fotoacústica do modelo $R G$

Assim, opticamente, podemos classificar as amostras comparando a sua espessura $l_{s}$ com o seu comprimento de absorção óptica $l_{\beta}$ :

Se $l_{s} \gg l_{\beta} \rightarrow$ amostra opticamente opaca.

Se $l_{s} \cong l_{\beta} \rightarrow$ amostra absorvedora.

Se $l_{s}<l_{\beta} \rightarrow$ amostra opticamente transparente.

Termicamente, a classificação é feita através da comparação entre a espessura da amostra $l_{s}$ e a profundidade que alcança o calor dentro da amostra, definido como comprimento de difusão térmica, $\mu_{s}$ :

Se $l_{s}<\mu_{s} \rightarrow$ amostra termicamente fina.

Se $l_{s}>\mu_{s} \rightarrow$ amostra termicamente grossa.
A quantidade de radiação transformada em calor fica relacionada diretamente com as propriedades de absorção, difusão e espessura da amostra absorvedora da radiação, que é baseada na Equação 2:

$$
\delta P(t)=\frac{\gamma P_{0} \theta(, \lambda)}{\sqrt{2} l_{g} \alpha_{g} T_{0}} e^{j\left(\omega t-\frac{\pi}{4}\right)}
$$

onde,

$\theta(\omega, \lambda)=\frac{\beta(\lambda) I_{0}}{2 K_{s}\left[\beta^{2}(\lambda)-\sigma(\omega)\right]}\left\{\frac{[r(\omega, \lambda)-1] e^{\sigma,(\omega) t}-[r(\omega, \lambda)+1][b-1] e^{\sigma,(\omega) t}+2[b-r(\omega, \lambda)] e^{\beta(\vartheta) t} t}{(g+1)(b+1) e^{\sigma,(\omega) t}-(g-1)(b-1) e^{\sigma,(\omega) t}}\right\}$

Aqui, $\gamma=\frac{c_{p}}{c_{v}}$ é a razão entre os calores específicos, $T_{0}$ é a temperatura média na superfície da amostra, $P_{0}$ é a pressão ambiente e $\omega=2 \pi \mathrm{f}$ é a frequência angular de modulação, $b=\frac{k_{b} \sigma_{b}}{k_{s} \sigma_{s}}, g=\frac{k_{g} \sigma_{g}}{k_{s} \sigma_{s}}$ e $r=(1-j) \frac{\beta}{2 a_{s}}$. A Tabela 1 apresenta as grandezas normalmente presentes nas equações fotoacústicas.

Tabela 1. Grandezas das equações

\begin{tabular}{ccc}
\hline Grandezas & Denominação & Unidades \\
\hline $\mathrm{k}$ & Condutividade térmica & $\mathrm{Wm}^{-1} \mathrm{~K}^{-1}$ \\
$\rho$ & Densidade de massa & $\mathrm{kgm}^{-3}$ \\
$\lambda$ & Comprimento de Onda & $\mathrm{m}$ \\
$\sigma$ & Coeficiente complexo de difusão térmica & $\mathrm{m}^{-1}$ \\
$\mathrm{f}$ & Frequência angular & $\mathrm{Hz}$ \\
$\beta$ & Coeficiente de absorção óptica & $\mathrm{m}^{-1}$ \\
$1_{\beta}=1 \beta^{-1}$ & Comprimento de absorção óptica & $\mathrm{m}$ \\
\hline
\end{tabular}

A Equação 2 indica a expressão geral da variação de pressão dentro da câmera fotoacústica, quando o mecanismo de difusividade térmica é predominante na geração do sinal fotoacústico. ${ }^{26}$ É importante ressaltar que a coluna fronteiriça de gás, $2 \pi \mu_{g}$, é que vai responder termicamente à variação periódica da temperatura na superfície da amostra, provocando um gradiente de pressão na camada de gás, resultando na formação de um pistão acústico, cuja variação de pressão é transformada em sinal fotoacústico, capturado pelo microfone embutido na célula fotoacústica.

\section{A Espectroscopia fotoacústica}

Esta técnica começou a ser aplicada no estudo da fotossíntese em 1976, por Adams M. J, ao obter o espectro fotoacústico de uma solução preparada a partir da clorofila extraída de folhas de espinafre. ${ }^{27}$ Dois anos depois, Rosencwaig mostrou ser possível obter o espectro fotoacústico de uma folha, colocando-a em uma célula fechada. ${ }^{24} \mathrm{Em}$ 1986, Perondi e Miranda apresentaram a Célula Fotoacústica Aberta (OPC).$^{28} \mathrm{E}$ poucos anos depois, a OPC também foi introduzida no campo de estudo da fotossíntese. ${ }^{26}$

Entre outras aplicações, a Espectroscopia Fotoacústica é empregada também na caracterização das propriedades térmicas da matéria, particularmente o da medida de difusividade térmica, ${ }^{2,29,30}$ efusividade térmica e do tempo de relaxação não radiativo. ${ }^{31} \mathrm{~A}$ difusividade térmica é um parâmetro que indica a velocidade com que o calor se propaga dentro da amostra, até chegar a um valorconstante. Por outro lado, a efusividade térmica indica a impedância térmica da amostra, isto é, o quanto de calor a amostra absorve de um meio externo. A capacidade térmica mostra o quanto de calor um material consegue armazenar dentro de seu volume. Finalmente, a condutividade térmica refere-se à velocidade com que o fluxo de calor incidente, 
que promove um aquecimento superficial na amostra, atinge as suas regiões mais frias. Todos estes parâmetros estão diretamente ligados às microestruturas da amostra e cada material apresenta propriedades térmicas únicas. Destaca-se a importância desta técnica na área de materiais biológicos, uma vez que possibilita o estudo in vivo, deixando intactas as amostras. ${ }^{26,32}$

Uma utilização bem apropriada para esta técnica é no estudo da fotossíntese, que se refere à utilização de energia química pelas plantas, para a produção de substancias orgânicas a partir do gás carbônico $\left(\mathrm{CO}_{2}\right)$ e da água $\left(\mathrm{H}_{2} \mathrm{O}\right)$. Na fase fotoquímica, durante a quebra das moléculas da água, que se formam as moléculas de oxigênio que são liberadas na atmosfera. Particularmente, o processo da fotossíntese implica em liberação - ou absorção - de gás, o que produz mudanças de pressão no volume restrito da câmara fotoacústica. Este efeito de variação de pressão foi chamado de efeito bárico. A componente bárica demora um período de tempo para ser observada, devido à complexa cadeia de reações fotoquímicas que deve ser percorrida até a liberação do $\mathrm{O}_{2}{ }^{33}$

Segundo Barja, ${ }^{19}$ a evolução do oxigênio é provocada na expansão isobárica do espaço intercelular com subsequente compressão adiabática do gás na câmara fotoacústica. Assim, pode-se medir a componente fotossintética da variação de pressão, isto é, $P_{O_{2}}$, de acordo com Equação 3

$$
P_{O_{2}}=\gamma_{T} R T_{0} \psi_{(t)}
$$

onde $R$ é a constante dos gases e $\psi_{(t)}$ é a oscilação média da concentração molar em torno do valor $P_{0} / R T_{0}$. Esta variação da concentração se relaciona com o fluxo modulado de oxigênio, $\mathrm{q}_{3}$, na interface $\left(\mathrm{z}=l_{2}+l_{3}\right)$ entre a parede celular e o espaço intercelularde acordo com a Equação 4.

$$
\psi_{(t)}=-i \frac{\eta_{c} \eta_{m} A q_{3}(t)}{\omega V_{T}},
$$

onde $i=\sqrt{-1}$ Sendo definido $\eta_{m} A$ como a área superficial total das células dos mesófilos para uma área foliar $\mathrm{A} ; \eta_{c}$ é a razão entre a área formada pela projeção dos cloroplastos no plano das paredes celulares e a área total $\left(\eta_{m} A\right)$ destas; $V_{T}$ representa o volume do gás na câmara fotoacústica e mais volume do espaço intercelular correspondente à área foliar A.

Depois que as clorofilas absorvem a luz incidente, o oxigênio é formado após uma sequência de reações de oxirredução. O sistema de fotossíntese possui clorofilas $a$ e $b$ em quantidades semelhantes, captando comprimentos de onda mais curtos que os captados pelos sistemas que possuem alta concentração de clorofila $a$, captando essencialmente radiações de comprimento de onda longo. Podemos escrever a componente fotossintética $\mathrm{P}_{\mathrm{O} 2}$ da variação de pressão na seguinte Equação 5:

$$
P_{O_{2}}=\frac{\gamma_{T} R T_{0} \eta_{c} \eta_{m} A \varnothing \beta C I_{0}}{8 \omega^{\frac{3}{2}} V_{T} \sqrt{1+\left(\frac{\omega}{k}\right)^{2}}} F e^{i(\varphi+\omega t)}
$$

onde o termo complexo $\mathrm{Fe}^{i(\varphi+\omega t)}$ depende da constante de tempo $\mathrm{k}$ de evolução de $\mathrm{O}_{2}$ das permeabilidades das membranas e também das espessuras $l_{1}, l_{2}$ e $l_{3}$, conforme a Figura 2. A pressão devida à taxa de evolução do $\mathrm{O}_{2}\left(P_{O_{2}}\right)$ é determinada por meio da dependência do ângulo de fase $\varphi$ da atividade fotossintética com a frequência de modulação.

Portanto, a luz incidente na folha chega aos cloroplastos e o oxigênio ali evoluído e difundido pelo estroma, passa pelas membranas, atravessando o citoplasma, a membrana plasmática e a parede da

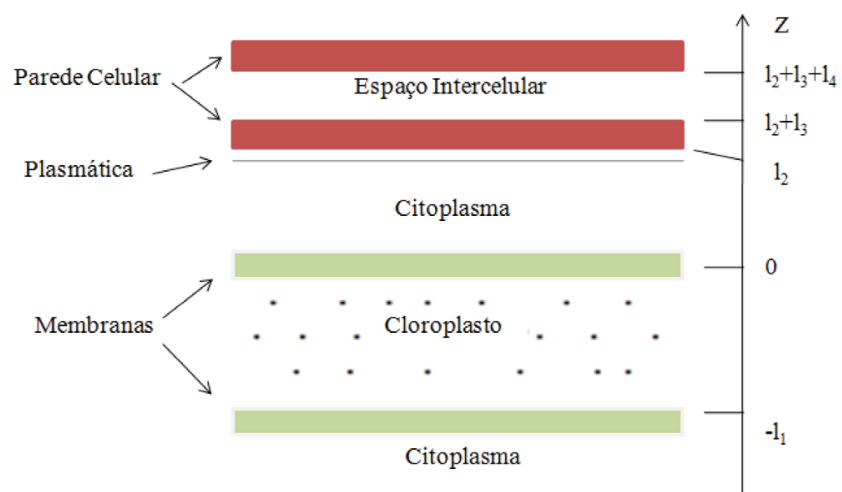

Figura 2. Seção transversal esquemática de célula do mesófilo (Figura fora de escala). O cloroplasto tem espessura $l_{1}$, o citoplasma $l_{2}$, a parede celular $l_{3}$ e o espaço intercelular $l_{4}$, (despreza-se a espessura das membranas celulares. Adaptação Barja ${ }^{19}$ )

célula até o espaço intercelular, aumentando a concentração do $\mathrm{O}_{2}$ e, consequentemente, a pressão neste meio. Para este fenômeno foi utilizado o sistema de espectroscopia fotoacústica de absorção no espectro do visível (PAS) como indicado na Figura 3, constituindo de uma lâmpada de xenônio como fonte de luz. Após a lâmpada de xenônio, existe um monocromador, para realizar uma varredura do comprimento de onda da luz modulada e em seguida a luz é modulada por um modulador mecânico, chopper..$^{21}$

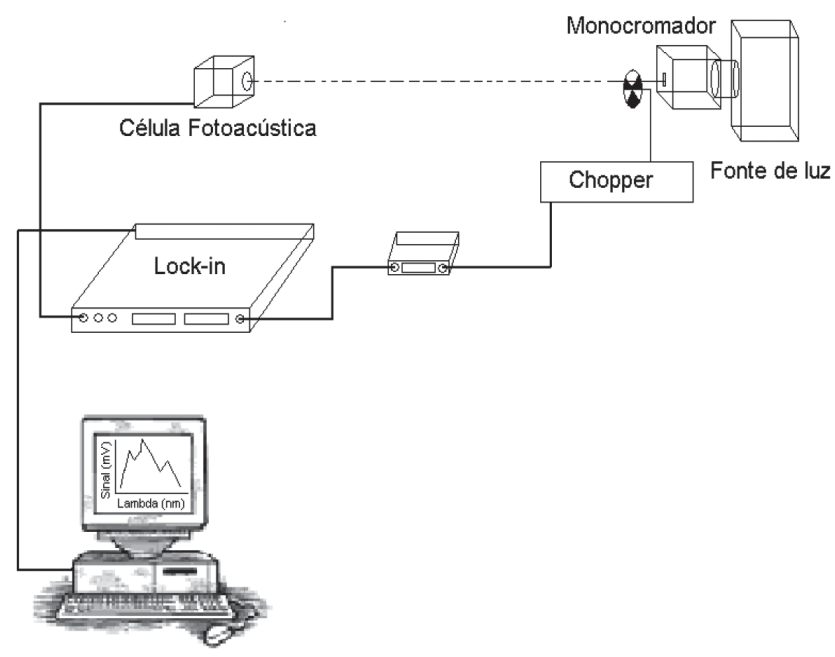

Figura 3. Esquema do Espectrômetro Fotoacústico

É importante ressaltar que em sistemas convencionais, esta taxa só pode ser medida depois de vários minutos, pela necessidade de se deixar acumular uma determinada densidade de $\mathrm{O}_{2}$. Enquanto que, usando a técnica fotoacústica, a evolução de $\mathrm{O}_{2}$ já é detectada logo no primeiro minuto.

A PAS é uma técnica simples que permite obter espectros de absorção nas regiões do ultravioleta ao infravermelho para uma grande variedade de materiais, tais como: sólidos, , líquidos, gases, pós, géis, filmes, entre outros, fornecendo tanto informações qualitativas como quantitativas sobre o material analisado. ${ }^{34} \mathrm{~A}$ amostra é colocada dentro de uma célula vedada preenchida por gás, na qual um feixe de luzvindo do chopper incide sobre a amostra, através de uma janela transparente (célula fotoacústica fechada). No interior da célula encontra-se um microfone capacitivo que, na realidade é o detector.

A energia da radiação modulada absorvida pela amostra é convertida em energia térmica, gerando flutuações de pressão dentro 
da célula. Essas flutuações são detectadas pelo microfone que as converte em sinal elétrico que neste sistema é chamado de sinal fotoacústico $\left(\mathrm{S}_{\mathrm{PA}}\right)^{24}$

O sinal fotoacústico obtido é proporcional ao produto do espectro de emissão da luz incidente, $I(v)$ e pela energia dos fótons absorvidos, hv. Grande parte da energia incidente na folha é armazenada como energia química, sendo posteriormente utilizada na síntese de compostos necessários ao desenvolvimento da planta pela fotossíntese. Este armazenamento diminui a quantidade de luz absorvida que é transformada em calor. Assim, este efeito é chamado de perda fotoquímica, que pode ser descrita conforme Equação 6, relacionado ao balanço de energia do sistema vegetal sob incidência de luz. ${ }^{33}$

$$
\mathrm{h} v=H+\phi h v_{f}+\eta \Delta \mathrm{E} .
$$

Como este produto difere para cada comprimento de onda, torna-se necessário normalizar os sinais medidos das amostras, pelo espectro da fonte de luz. Normalmente, para determinar este espectro, utiliza-se um carvão padrão.

Os diferentes mecanismos, através dos quais os pulsos de calor produzidos na amostra geram ondas acústicas no gás, são basicamente três: a difusão de calor da amostra para o gás, a expansão térmica da amostra e a flexão termoelástica da mesma. A ocorrência ou não de um ou outro mecanismo e a predominância de um sobre o outro dependem das condições experimentais, bem como do material a ser estudado. ${ }^{31,35} \mathrm{~A}$ expansão térmica pode ser entendida como o aquecimento periódico da amostra (devido aos pulsos de calor na amostra), acarretando uma oscilação da temperatura média. Como consequência, a amostra expande e contrai periodicamente, de forma que sua superfície em contato com o ar passa a funcionar como um pistão vibratório, gerando ondas acústicas no gás. ${ }^{31,35} \mathrm{~A}$ flexão termoelástica surge devido à existência de um gradiente de temperatura ao longo da espessura da amostra, pois a absorção decresce à medida que a luz penetra no material. ${ }^{31,35}$ Este gradiente de temperatura faz com que a expansão térmica seja diferente para diferentes planos da amostra (perpendiculares ao gradiente), induzindo a uma flexão da mesma na direção do gradiente, se suas bordas estiverem presas. Este processo é também periódico (semelhante à vibração da membrana de um tambor), gerando ondas acústicas no gás. Na difusão térmica, o pulso de calor produzido na amostra é transmitido ao gás, que ao expandir-se periodicamente, gera a onda acústica. As ondas acústicas também podem ser geradas a partir da variação do número de moléculas na câmera fotoacústica. Este é o caso das folhas vegetais, onde se tem o consumo do $\mathrm{CO}_{2}$ e a indução do $\mathrm{O}_{2}$ durante a reação da fotossíntese. Uma vez que a luz incidente é modulada, tanto o consumo de $\mathrm{CO}_{2}$ quanto a indução do $\mathrm{O}_{2}$ serão também modulados.

Desde os primeiros estudos da aplicação da Espectroscopia Fotoacústica em folhas vegetais, ${ }^{36}$ muitos trabalhos são feitos com pedaços da folha, isto é, tem que seccionar a folha para inserí-la dentro da célula fotoacústica. No entanto, o uso da técnica OPC permite que as medidas sejam feitas "in vivo", ou seja, diretamente com a folha na própria planta. ${ }^{37}$

\section{PARTE EXPERIMENTAL}

\section{Tratamentos e instalação e condução do experimento em casa de vegetação}

O experimento foi conduzido em delineamento em blocos cazualizados ( 3 blocos) com quatro tratamentos sendo eles: 1 - com biochar; 2 - com FMA; 3 - com biochar + FMA; 4 - testemunha (sem biochar e sem FMA) nestes tratamentos foram cultivadas plantas de mamoeiro Golden (Carica Papaya L) em vasos de $4 \mathrm{dm}^{3}$.
O experimento foi realizado na casa de vegetação do laboratório de solos da Universidade Estadual do Norte Fluminense, para tal foram coletadas amostras de um solo argiloso do município de São Francisco de Itabapoana- RJ.Sendo previamente seco ao ar e à sombra por 5 dias.

Após serem secas, as amostras de solo foram encaminhadas ao Laboratório de Análise de Solos da Universidade Federal Rural do Rio de Janeiro para a realização das análises químicas, de acordo com a Tabela 2. O solo foi separado em amostras de $4 \mathrm{dm}^{3}$. Cada amostra recebeu $0,29 \mathrm{~g} \mathrm{dm}^{-3} \mathrm{de}$ calcário (PRNT- Poder Real de Neutralização Total de calcário 80\%), com recomendação baseada na análise do solo e para elevação da Saturação de bases para $60 \%$. O solo foi homogeneizado e mantido a $60 \%$ da sua capacidade de campo em sacos plásticos sobre a bancada da casa vegetal para incubação. Após 30 dias da calagem o solo foi adubado com $15 \mathrm{mg} \mathrm{dm}^{-3}$ de P na forma de fosfato de rocha e em seguida foram submetidos aos tratamentos, ou seja a aplicação do biochar e inoculo da micorriza.

Tabela 2. Caracterização química do solo utilizado antes da instalação do experimento (Metodologia de acordo com Embrapa ${ }^{38}$ ) (Média de 3 repetições) ${ }^{39}$

\begin{tabular}{cccc}
\hline Características & Valores & Características & Valores \\
\hline $\mathrm{pH}^{*}$ & 5,3 & $\mathrm{C}(\%)$ & 0,96 \\
$\mathrm{P}\left(\mathrm{mg} \mathrm{dm}^{-3}\right)^{* *}$ & 5,0 & $\mathrm{~m}(\%)$ & 0,0 \\
$\mathrm{~K}\left(\mathrm{mg} \mathrm{dm}^{-3}\right)^{* * *}$ & 100 & $\mathrm{~V}(\%)$ & 48 \\
$\mathrm{Ca}\left(\mathrm{cmol}_{\mathrm{c}} \mathrm{dm}^{-3}\right)^{* * *}$ & 1,0 & $\mathrm{MO}\left(\mathrm{g} \mathrm{dm}^{-3}\right)^{* * * * *}$ & 16,6 \\
$\mathrm{Mg}\left(\mathrm{cmol}_{\mathrm{c}} \mathrm{dm}^{-3}\right)^{* * * *}$ & 0,5 & $\mathrm{Fe}\left(\mathrm{mg} \mathrm{dm}^{-3}\right)^{* *}$ & 32,0 \\
$\mathrm{Al}\left(\mathrm{cmol}_{\mathrm{c}} \mathrm{dm}^{-3}\right)^{* * *}$ & 0,0 & $\mathrm{Cu}\left(\mathrm{mg} \mathrm{dm}^{-3}\right)^{* *}$ & 0,4 \\
$\mathrm{H}+\mathrm{Al}\left(\mathrm{cmol}_{\mathrm{c}} \mathrm{dm}^{-3}\right)^{* * * *}$ & 1,9 & $\mathrm{Zn}\left(\mathrm{mg} \mathrm{dm}^{-3}\right)^{* * *}$ & 1,4 \\
$\mathrm{Na}\left(\mathrm{cmol}_{\mathrm{c}} \mathrm{dm}^{-3}\right)^{* * *}$ & 0,02 & $\mathrm{Mn}\left(\mathrm{mg} \mathrm{dm}^{-3}\right)^{* * *}$ & 5,9 \\
$\mathrm{SB}\left(\mathrm{cmol}_{\mathrm{c}} \mathrm{dm}^{-3}\right)$ & 1,8 & $\mathrm{~B}\left(\mathrm{mg} \mathrm{dm}^{-3}\right)^{* *}$ & 0,18 \\
$\mathrm{~T}\left(\mathrm{cmol}_{\mathrm{c}} \mathrm{dm}^{-3}\right)$ & 3,7 & & \\
$\mathrm{t}\left(\mathrm{cmol}_{\mathrm{c}} \mathrm{dm}^{-3}\right)$ & 1,8 & & \\
\hline
\end{tabular}

pH em água; ** Mehlich $\left(\mathrm{H}_{2} \mathrm{SO}_{4} 0,0125 \mathrm{~mol} \mathrm{~L}^{-1}+\mathrm{HCl} 0,05 \mathrm{~mol} \mathrm{~L}^{-1}\right),{ }^{* * *} \mathrm{KCl}$ $1 \mathrm{~mol} \mathrm{~L}^{-1},{ }^{* * * * *}$ Acetato de cálcio $\mathrm{pH} 7,{ }^{* * * * * *}$ dicromato de potássio/colorimétrico.

O biochar foi produzido a partir da pirólise de cama de aviário a uma temperatura de $400{ }^{\circ} \mathrm{C}$, sendo homogeneizado antes da deposição nos vasos. $\mathrm{O}$ biochar apresentou $267 \mathrm{~g} \mathrm{dm}^{3}$ de densidade aparente e a caracteristica química de acordo com a Tabela 3. O biochar foi aplicado no solo a $1 \% \mathrm{~V} / \mathrm{V}$ correspondendo a $2,7 \mathrm{~g} \mathrm{dm}^{3}$ de solo.

O fungo micorrízico utilizado da espécie Rhyzophagus Clarum, pertencente ao banco de inóculos do Laboratório de Microbiologia do Solo/CCTA/UENF, previamente multiplicada em plantas de Brachiaria brizantha. $\mathrm{O}$ inoculante constou de um solo inóculo, contendo cerca de 1200 esporos $/ \mathrm{dm}^{3}$ de inoculantes, suas raízes colonizadas e hifas.

Foram adicionados ao solo incubado 110,4 $g$ inóculo de micorriza para os tratamentos contendo FMA, $11 \mathrm{~g}$ de biochar por vaso para os tratamentos contendo biochar. As amostras de solo junto com o biochar e/ ou FMA foram homogeneizadas e, logo após, depositadas nos vasos de $4 \mathrm{dm}^{3}$ de capacidade.

Em seguida, foram semeadas seis sementes de mamão por vaso. As sementes de mamão foram inicialmente lavadas para a retirada do sarcotesta que envolve a semente para facilitar a germinazação.

Após 20 dias do semeio, foi realizado um desbaste, mantendo-se uma única planta de porte médio em cada vaso. As plantas foram irrigadas diariamente com água filtrada e deionizada e monitoradas quanto ao aparecimento de pragas, doenças e sintomas de deficiência nutricional. Passados 80 dias do semeio, as plantas sob tratamento de 
Tabela 3. Caracterização química do biochar utilizado para montagem do experimento. Metodologia adotada para resíduos de acordo com Embrapa ${ }^{38}$

\begin{tabular}{|c|c|c|c|c|c|c|c|c|c|c|c|}
\hline $\mathrm{pH}$ & $\mathrm{N}$ & $\mathrm{P}_{2} \mathrm{O}_{5}$ & $\mathrm{~K}_{2} \mathrm{O}$ & $\mathrm{Ca}$ & $\mathrm{Mg}$ & S & C & $\mathrm{Fe}$ & $\mathrm{Cu}$ & $\mathrm{Zn}$ & $\mathrm{Mn}$ \\
\hline & ----- & ----. & 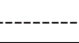 & 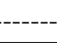 & 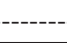 & 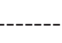 & ---.. & 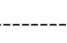 & $\mathrm{ng}$ & .... & 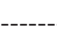 \\
\hline 8,9 & 42,91 & 27,62 & 62,32 & 6,7 & 9,04 & 5,2 & 331,2 & 1620 & 636 & 588 & 588 \\
\hline
\end{tabular}

controle apresentaram sintomas de deficiência nutricional recebendo, então $0,025 \mathrm{~g} \mathrm{dm}^{-3}$ de $\mathrm{N}$ e $0,1 \mathrm{~g} \mathrm{dm}^{-3}$ de $\mathrm{K}$ nas formas de uréia e $\mathrm{KCl}$, respectivamente, permanecendo por mais 40 dias nos vasos sob irrigação. As folhas foram contabilizadas. Foi então realizada a leitura do SPAD na terceira folha a partir do ápice e, por meio do determinador portátil de Clorofila SPAD-502.40 A parte aérea das plantas foi cortada, seca em esturfas de circulação forçada de ar a $65{ }^{\circ} \mathrm{C}$ por 72 horas, em seguida foi determinada o peso da biomassa seca. Esta foi moída e submetida a digestão sulfúrica onde foi determinado o teor de Nitrogênio. O conteúdo de Nitrogênio foi obtido pela multiplicação do teor pelo peso da parte aérea.

\section{Análises realizadas no Laboratório de Ciências Físicas no Centro de Ciências Tecnológicas da Universidade Estadual do Norte Fluminense Darcy Ribeiro (LCFIS-CCT-UENF)}

No laboratório de Ciências Físicas (LCFIS) da UENF, foi utilizada a espectroscopia fotoacústica de absorção de luz no visível com o objetivo de identificar os picos de absorção das clorofilas $a$ e $b$ e da cutícula das folhas de mamão retiradas dos vasos aos 120 dias após o semeio. O sistema de medidafoi constituído de uma fonte de luz, neste caso, uma lâmpada de xenôniode alta pressão a arco (Oriel Corp., modelo 6269) de $1000 \mathrm{~W}$ de potência, cujo feixe foi periodicamente interrompido por um modulador mecânico (Princeton AppliedResearch, modelo 192). Um monocromador (Oriel Corp., modelo 77250) de 0,25 m de distância focal com uma rede de difração de 300 linhas por milímetro (Oriel Corp., modelo 77300) para a seleção dos comprimentos de onda de interesse. A frequência de modulação usada é $17 \mathrm{~Hz}$. O feixe de luz modulado incide diretamente na amostra que é inserida na célula fotoacústica fechada (MTEC modelo 300). O sinal do microfone da célula é enviado para o amplificador Lock-in da Stanford modelo SR830 e os dados foram coletados pelo computador. O espectro da lâmpada de xenônio é registrado, utilizando-se um carvão padrão e está representado para o intervalo de comprimento de onda de $250 \mathrm{~nm}$ a $750 \mathrm{~nm}$. O sinal das amostras de folhas é normalizado com o sinal do carvão.

Foram utilizados para a espectroscopia fotoacústica, a segunda ou a terceira folha a partir da base das plantas de mamão com 120 dias de cultivo.

\section{RESULTADOS E DISCUSSÃO}

\section{Crescimento e nutrição do mamoeiro}

Plantas cultivadas sem micorriza e sem biochar (testemunha) apresentaram menor número de folhas (Figura 4) que as plantas cultivadas em presença desses componentes.

A Figura 5 apresenta fotografias das mudas de mamoeiros, aos 120 dias de cultivo, com os diferentes tratamentos. Foram observados que as mudas do controle (testemunha) apresentaram clorose (ficaram amareladas) e também menor crescimento em relação aos demais tratamentos.

Observa-se que as plantas das Figuras 5(a), 5(b) e 5(d) apresentaram uma cor verde (clorofila) mais intensa, ou seja, sinalizando uma planta com melhor qualidade nutricional aos tratamentos com micorrizas, micorrizas+biochar e biochar respectivamente. Já a planta referente à Figura 5(c) (testemunha) apresentou folhas amareladas, indicando uma planta com baixa eficiência metabólica. A ausência da cor verde indica a falta de clorofila.

O número de folhas na planta inoculada com micorriza aumentou porque, além de melhorar o estado nutricional das mudas, os FMAs aceleram seu crescimento e promovem um maior vigor na fase de sua formação. ${ }^{41}$ Também favorece a adaptação das plantas a diferentes ecossistemas, aumentando a tolerância a fatores bióticos e abióticos estressantes. ${ }^{42} \mathrm{O}$ biochar apresenta nutrientes na sua composição e parte desses nutrientes está disponível para plantas (Tabela 2). A micorriza juntante com o biochar proporciona um efeito aditivo positivo na planta como pode ser observado na Figura 5(a) indicando planta com maior vigor.

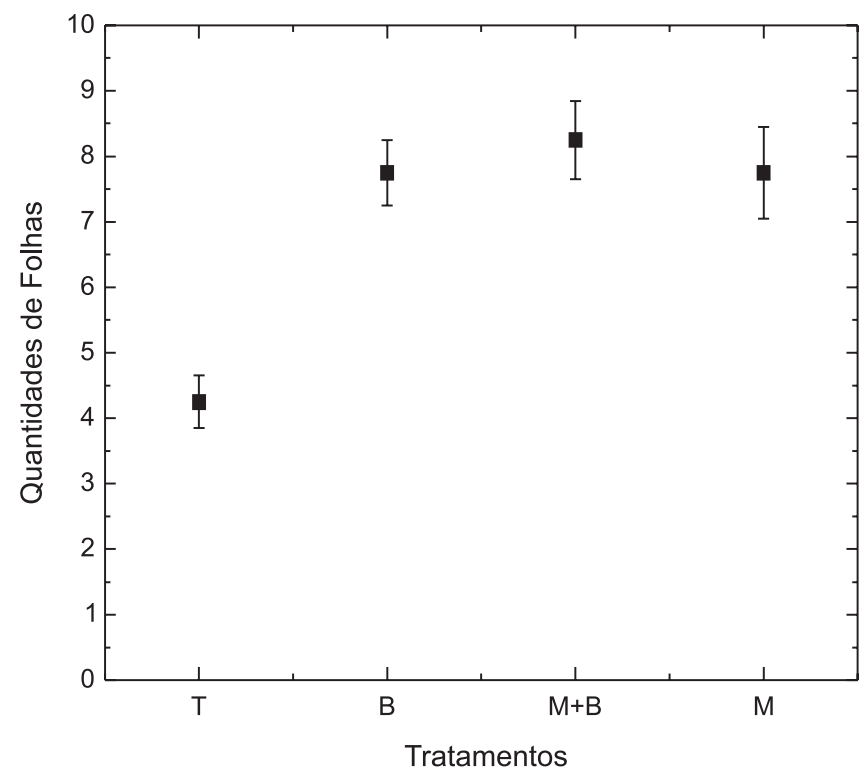

Figura 4. Quantidades das folhas em plantas de mamoeiros aos 120 dias de cultivo em solos com: testemunha (T), B (Biochar), $M+B$ (Micorriza e Biochar) e M (Micorriza)

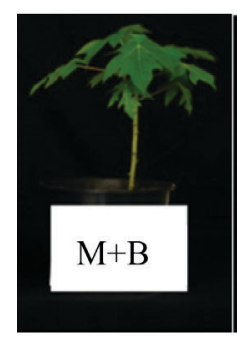

(a)

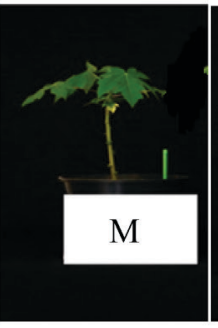

(b)

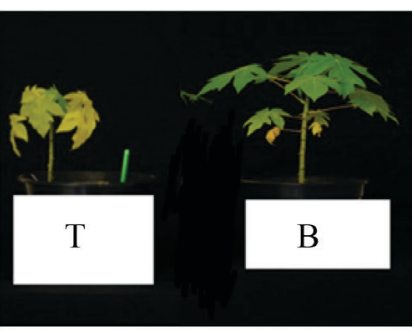

(c) (d)
Figura 5. Fotografias das mudas de mamão cultivadas por 120 dias: a) mamoeiro cultivado em solo tratado com micorriza e biochar $(M+B)$; b) cultivado em solo tratado com adição de micorriza $(M)$; c) mamoeiro cultivado em solo sem tratamento $(T)$; d) mamoeiro cultivado em solo tratado com biochar $(B)$

Uma forma de quantificação dos pigmentos fotossintéticos (clorofila e carotenóides) pode ser realizada por meio do determinador portátil de clorofila SPAD $-502 .{ }^{40} \mathrm{Na}$ análise da intensidade de cor 
verde, medida pelo SPAD (Figura 6), a segunda folha do mamoeiro aos 120 dias de cultivo, contando a partir do ápice, percebeu-se uma maior intensidade nas plantas do tratamento com micorriza + biochar, seguido do tratamento com aplicação somente de biochar e, após, somente de micorriza. As plantas do tratamento controle apresentaram uma menor intensidade de cor verde, confirmando o que é visualizado na Figura 3(c), ou seja, as plantas encontram-se visivelmente mais amareladas. A coloração verde está associada ao teor de clorofila da folha. A molécula de clorofila apresenta nitrogênio em sua estrutura. Assim é importante a avaliação da quantidade de Nitrogênio pelas folhas.

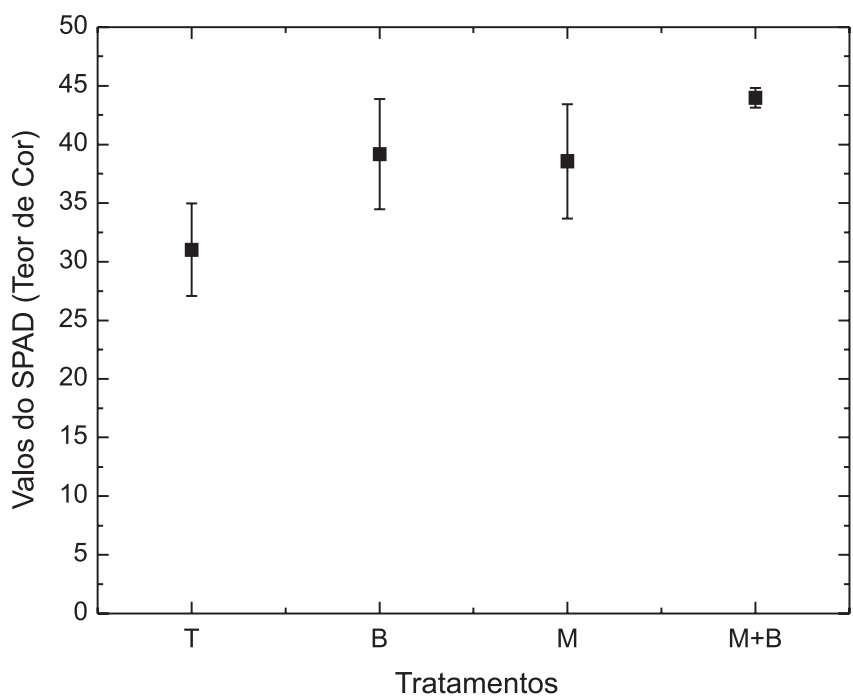

Figura 6. Valores médios da leitura do SPAD (intensidade de cor verde) em folhas de plantas de mamão cultivado por 120 dias com os tratamentos $T$ (testemunha), B (Biochar), M+B (Micorriza e Biochar), M (Micorriza)

A análise foliar, que é uma das técnicas utilizadas para a avaliação do estado nutricional das plantas, possibilita verificar a ocorrência de deficiências, toxidez ou desequilíbrio de nutrientes. No conteúdo de Nitrogênio foi observado menor valor no controle e maior no tratamento M, M + B e B. Segundo Silva et al., ${ }^{43}$ o nitrogênio é considerado um dos nutrientes com maiores incrementos na produtividade do mamoeiro. Cruz et al.,${ }^{44}$ relatam que o mamoeiro sob deficiência de nitrogênio pode acarretar na redução do crescimento e alteração na massa seca. Para a variedade Golden, todos os parâmetros de crescimento das plântulas do mamoeiro podem ser prejudicados pela deficiência de nitrogênio, sendo a área foliar o componente mais afetado. ${ }^{45}$

O conteúdo de nutrientes, analisado na Figura 7, retrata a quantidade do elemento que foi acumulado na planta. No presente experimento o FMA aumentou em torno de $1050 \%$ a aquisição do Nitrogênio, no entanto o FMA + Biochar aumentou a aquisição de Nitrogênio e em torno de $2164 \%$ em relação à testemunha e só a aplicação do biochar apresentou em aumento atual de $3374 \%$ também em relação à testemunha. $\mathrm{O}$ maior acréscimo no conteúdo de Nitrogênio no tratamento com biochar ocorreu, provavelmente porque somente a planta utilizou o nitrogênio e já no tratamento com FMA e FMA + Biochar, as micorrizas também utilizaram o nitrogênio, reduzindo, assim, no conteúdo na planta. Apesar disso, na leitura do SPAD (intensidade de cor verde) os valores não diferiram (Figura 6) entre os tratamentos $\mathrm{M}+\mathrm{B}, \mathrm{M}$ e B, confirmando o aspecto visual observado na Figura 5, onde somente as plantas do controle estão amareladas.

As relações simbióticas mutualísticas das micorrizas com as raízes das plantas são associações que propiciam a absorção de nutrientes. ${ }^{46}$ No entanto, os microrganismos também requerem os

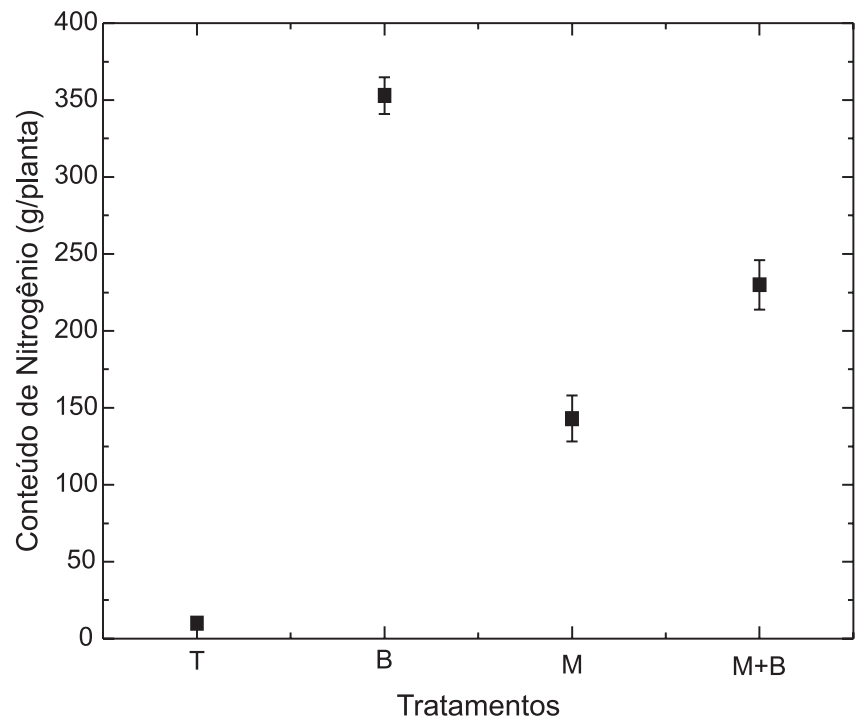

Figura 7. Conteúdo de nitrogênio em folhas de mamoeiro aos 120 dias de cultivo em solo com os seguintes tratamentos: controle $(T)$, Biochar (B), Micorriza+Bichar $(M+B)$ e Micorriza $(M)$

nutrientes para seu metabolismo. O baixo conteúdo do nitrogênio na testemunha (Figura 7) provavelmente acarretou a clorose visível nas folhas (Figura 5C) que foram também identificados pelo menor valor na intensidade de cor verde avaliada pelo SPAD (Figura 6). Torres Netto et al..${ }^{40}$ correlacionaram a leitura do SPAD ao teor de clorofila e também aos teores de Nitrogênio.

\section{Análise fotoacústica em folhas de mamão em função de diferentes manejos}

Foram obtidos os espectros das folhas de mamoeiros cultivados em solos tratados com FMA, com biochar, com biochar + micorrizas e em plantas não submetidas a tratamentos (testemunha).

Para qualificar a eficiência da aplicação do biochar e das micorrizas, foram avaliados os espectros de duas folhas de mamoeiro (Figura 8) cultivadas no solo tratado com $\mathrm{M}+\mathrm{B}$ e em ausência desses

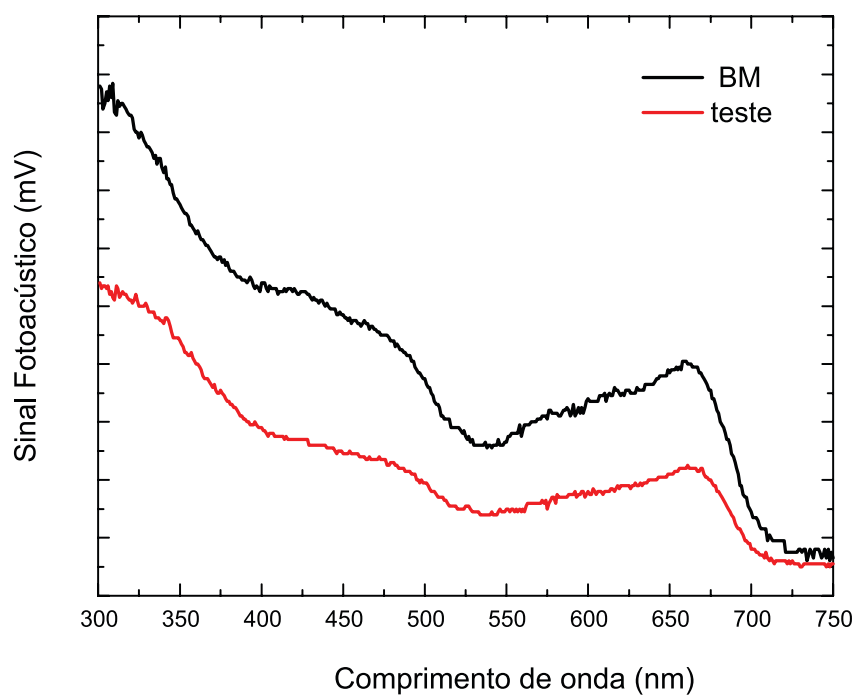

Figura 8. Espectros de absorção para a luz visível de folhas de mamoeiro cultivado por 120 dias em solo que recebeu o seguinte tratamento: $(M+B)$ com Micorriza e com Biocarvão (BM); Testemunha (T) sem Micorriza e sem Biocarvão. Picos de absorção da cutícula em $\sim 320 \mathrm{~nm}$, da clorofila b em $480 \mathrm{~nm}$ e da clorofila a em $\sim 680 \mathrm{~nm}$ 
componentes (T). Os picos de absorção concordam com os comprimentos de onda típicos da espectroscopia de absorção no visível de folhas, isto é, por volta de 320, 480 e $680 \mathrm{~nm}$ que representam a cutícula, (a cera que protege a folha contra agentes externos), o pico mais dominante da clorofila $b$ e o pico mais dominante da clorofila $a$, respectivamente. ${ }^{47}$ Como ilustrados na Figura 8 , nota-se uma maior absorção por parte da cutícula e das clorofilas $a$ e $b$ no espectro para otratamento $\mathrm{M}+\mathrm{B}$, demonstrando a eficiência desse tratamento, apresentando, ainda, um reforço na cutícula das folhas.

Para uma melhor visualização dos dados, os gráficos foram reduzidos às médias das repetições e em seguida foram coletadas apenas as intensidades relativas dos picos de absorção, em função dos comprimentos de onda relacionados às clorofilas $(a$ e $b)$ e cutícula. Por fim, as medidas de todas as folhas foram reunidas na Figura 9.

É possível notar que a folha das plantas submetidas ao tratamento Micorriza+Biochar (Figura 9B) mostrou uma melhor eficiência na fotossíntese e no fortalecimento da cutícula em relação às plantas do solo da testemunha (Figura 9A). Justifica-se este maior rendimento devido à presença da micorriza junto com o biochar. Como já dito anteriormente, a associação micorrízica está diretamente envolvida na nutrição mineral das plantas, favorecendo seu crescimento e
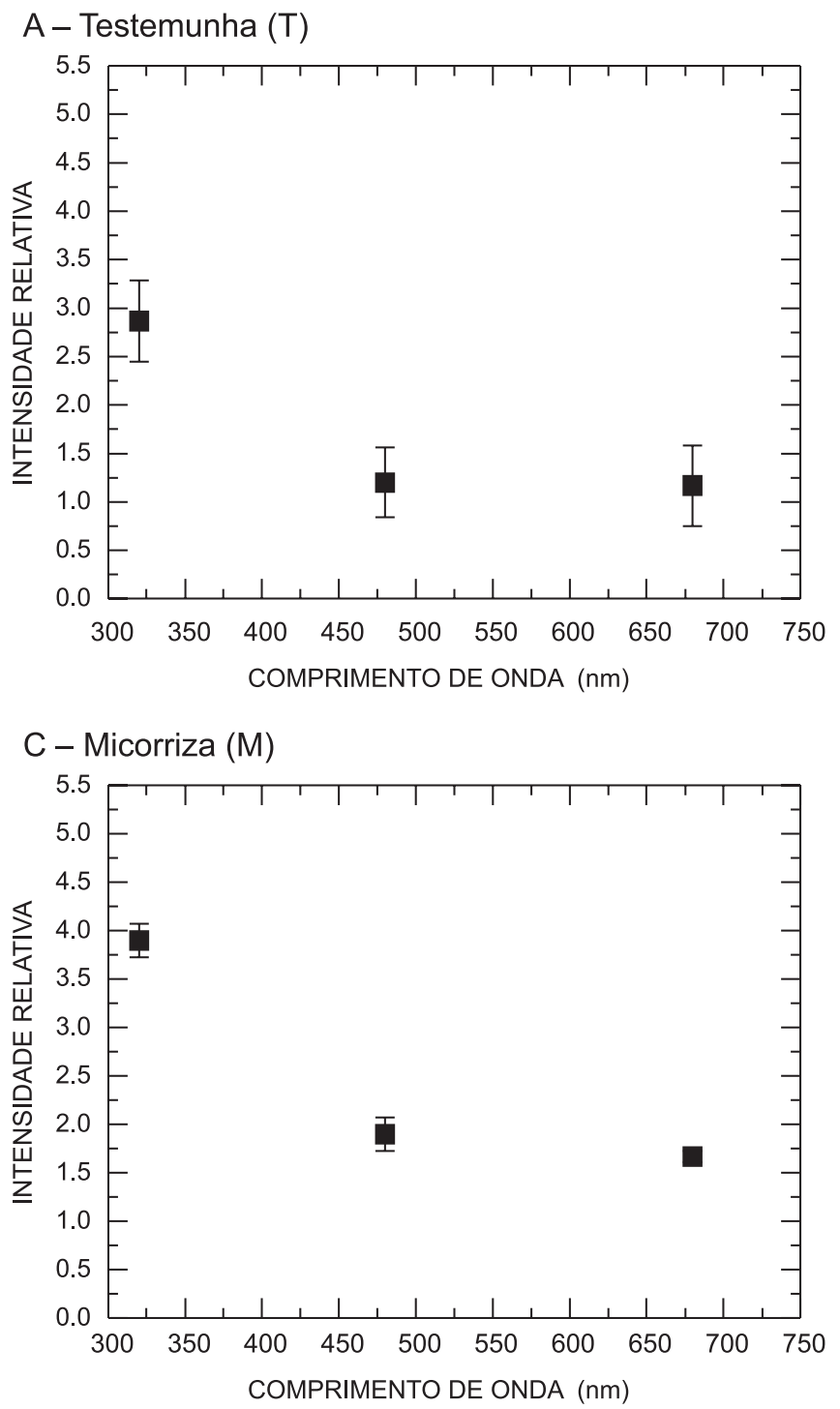

desenvolvimento. Esse benefício ocorre porque esses fungos colonizam o sistema radicular dos vegetais e expandem suas hifas no solo, absorvendo água e nutrientes e transferindo-os para as raízes colonizadas. Além disso, a planta, ao produzir fotossintato no processo de fotossíntese, transfere esses compostos carbônicos para a micorriza. A queda no teor de fotossintato na planta é um estímulo para a planta aumentar ainda mais a taxa fotossintética.

Observa-se que o tratamento com Biochar (Figura 9D) apresentou um pico nas clorofilas $a$ e $b$ maior que o da folha das plantas cultivadas como no tratamento com micorriza (Figura 9C). Pode-se justificar que o biochar apresenta nutrientes provenientes da biomassa original (cama de frango), que estão acumulados nos seus poros e que se encontram em forma prontamente disponível para a planta, ${ }^{48}$ que podem ser assimilados e incorporados a moléculas carbônicas reduzidas pela fotossíntese, estimulando mais a taxa fotossintética no tratamento com biochar.

O cultivo das plantas em solos com o tratamento biochar e micorriza proporcionou um efeito aditivo no estímulo à taxa fotossintética, não somente pela maior demanda de carboidratos para nutrir também as micorrizas, mas, além disso, por estas transferirem por meio das suas hifas os elementos químicos presentes no biochar para a planta hospedeira.
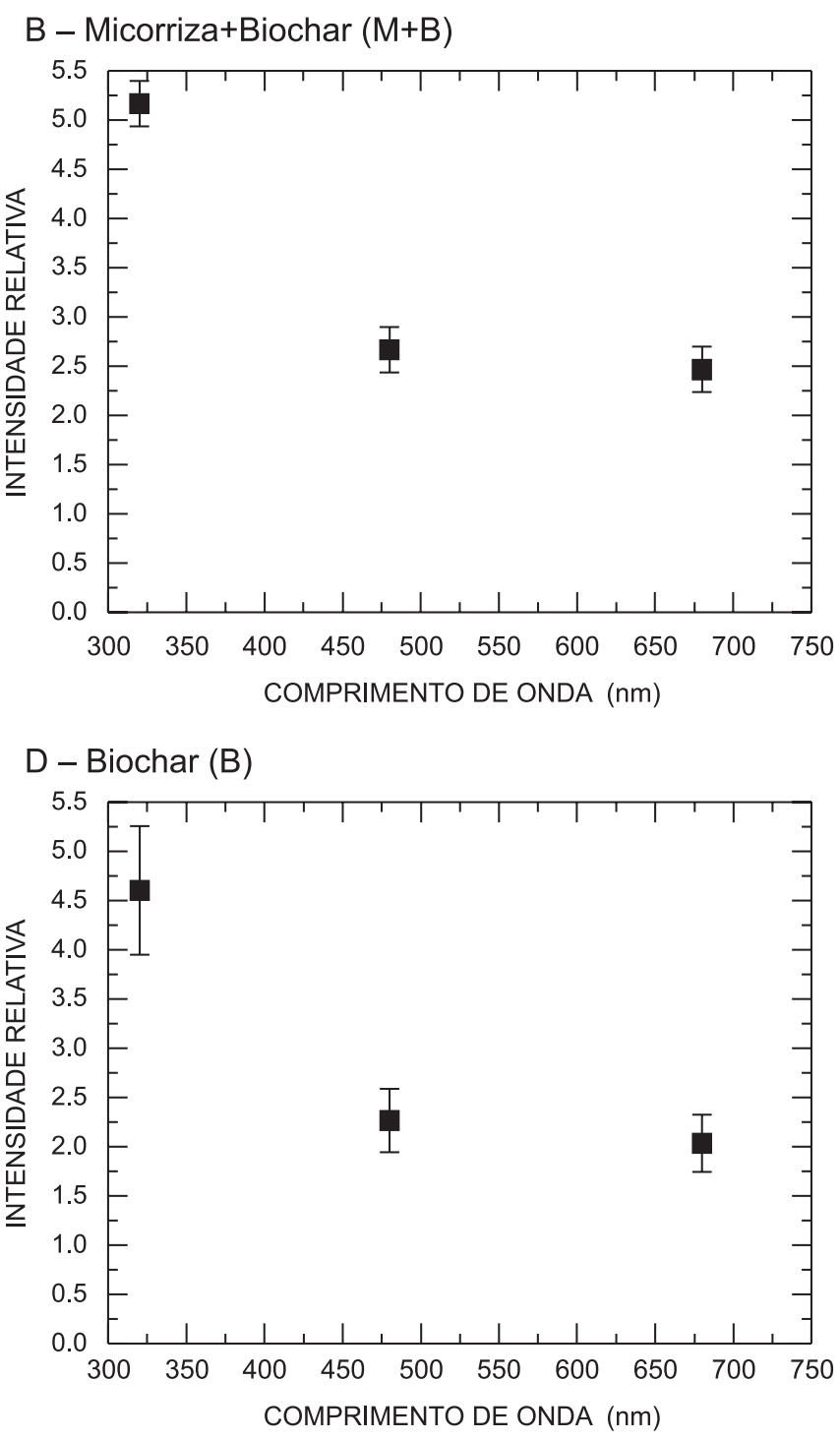

Figura 9. Amplitude Relativa para a absorção na luz visível de folhas de mamoeiro cultivado em solos com os seguintes tratamentos: A) sem micorriza e sem biochar (T); B) com micorriza e com biochar $(M+B)$; $C$ ) com micorriza e sem biochar (M); D) sem micorriza e com biochar(B). Picos de absorção da cutícula em $\sim 320 \mathrm{~nm}$, da clorofila b em $\sim 480 \mathrm{~nm}$ e da clorofila a em $\sim 680 \mathrm{~nm}$ 


\section{CONCLUSÃO}

Através da atividade da fotossíntese, analisou-se a nutrição da planta. Assim, indiretamente, foi analisada a eficiência dos tratamentos no solo.

A aplicação de Biochar, de Micorriza ou Micorrica + Biochar proporciona um aumento no crescimento e no conteúdo de nitrogênio das folhas e maior intensidade de cor verde (SPAD) no mamoeiro, reduzindo a clorose observada nas plantas sem esses tratamentos.

O conteúdo de nitrogênio aumentou em torno de $1050 \%, 2164 \%$ e $3374 \%$ com a aplicação da micorriza, da micorriza associada ao biochar e da aplicação somente do biochar, respectivamente.

Verificou-se também a eficiência na aplicação da técnica fotoacústica nas plantas de mamão cultivadas em solo argiloso tratado com biochar, com micorriza e com biochar associado à micorriza. Pela técnica espectroscópica de absorção na faixa do visível, foram obtidos espectros da fotossíntese (clorofila $a$ e clorofila $b$ ), bem como da cutícula de folhas de mamoeiro plantadas nestes solos em estudo, sendo os picos das clorofilas $a$ e $b$ maiores nos tratamentos com Micorriza associada ao Biochar. $\mathrm{O}$ espectro do pico de absorção para a cutícula da planta do tratamento controle foi menor que nos demais tratamentos, indicando plantas com cuticula mais frágeis, ou seja, menos densas, em comparação às plantas cultivadas com micorriza e biochar.

Como alternativa às técnicas convencionais, a técnica fotoacústica apresentou respostas mais rápidas e com alta sensibilidade às mudanças morfológicas das amostras.

\section{AGRECIMENTOS}

Os autores agradecem ao Prof. Cláudio Roberto Fonseca Sousa Soares, do laboratório de solos da Universidade Federal de Santa Catarina (UFSC), por fornecer o biochar, à CAPES (Coordenação de Aperfeiçoamento de Pessoal de Nível Superior) e à FAPERJ (Fundação de Amparo à Pesquisa do Estado do Rio de Janeiro) pelo suporte financeiro.

\section{REFERÊNCIAS}

1. Fernandes, C.; Corá, J. E.; Hortic. Bras. 2000, 18, 471.

2. Kern, D. C.; Costa, M.L.; Geociências 1997, 16, 141.

3. Pessoa Jr., O.; César, C. L.; Patel, N. A.; Vargas, H.; Ghizoni, C. C.; Miranda, L. C. M.; J. Appl. Phys. 1986, 59, 1316.

4. Heckenberger M. J.; Kuikuro A.; Kuikuro U. T.; Russell J. C.; Schmidt M.; Fausto C.; Franchetto, B.; Science 2003, 301, 1710.

5. Schmidt, M. W. I.; Noack, A. G.; Global Biogeochem. Cycles 2000, 14, 777.

6. Hossain, M. K.; Strezov, V.; Chan, K. Y.; Ziolkowski, A.; Nelson, P. F.; J. Environ. Manage. 2011, 92, 233.

7. Lima, S. L.; Marimon Jr., B. H.; Petter, F. A.; Tamiozzo, S.; Buck, G. B.; Marimon, B. S.; Acta Scientia 2013, 35, 2.

8. Ulyett, J.; Sakrabani, M.; Kibblewhite, M.; Hann, M. ; Eur. J. Soil Sci. 2014, 65, 96

9. Embrapa. Empresa Brasileira de Pesquisa Agropecuária; Manual de análises químicas de solos, plantas e fertilizantes $2^{\mathrm{a}}$ ed., Embrapa Solos: Brasília, 2005.

10. Smith, S. E.; Read, D. J.; Mycorrhizal symbiosis, $3^{\text {rd }}$ ed., Academic Press, Boston, 2008.

11. Souza, F. A.; Silva, E. M. R.; Micorrizas arbusculares na revegetação de áreas degradadas In: Avanços em fundamentos e aplicação de micorrizas; Siqueira, J. O., ed.; UFLA-DCS/DCF: Lavras: 1996, pág. 255.

12. Smith, S. E.; Read, D. J.; Mycorrhizal symbiosis, $2^{\text {nd }}$ ed., California Academic, San Diego, 1997.
13. Marschner, H.; Nutrient dynamics at the soil-root interface (Rhizosphere), In: Mycorrhizas in Ecossystems; Read, D. J.; Lewis, D. H.; Fitter, A. H.; Alexander, I. J. eds.; CAB Internacional: Cambridge, 1994, pág 3.

14. Rodrigues, L. A.; Martins, M. A.; Salomão, M. S. M. B.; Rev. Bras. Ciênc. Solo, 2003, 27, 4.

15. Janos, D.; Myccorhizas, succession, and the rehabilitation of deforested lands in the humid tropics. In Fungi and Environmental Change (British Mycological Society Symposia); Frankland, J.; Magan, N.; Gadd, G. eds.; Cambridge University Press: Cambridge 1996, pág 129,

16. Gryndler, M.; Sudová, R.; Püschel, D.; Rydlová, J.; Janousková, M.; Vosátka, M.; Bioresour. Technol. 2008, 99, 6391.

17. Killham, K.; Environ. Pollut. 1985, 38, 283.

18. Warnock, D. D.; Lehmann, J.; Kuyper, T. W.; Rillig, M. C.; Plant Soil 2007, 300, 9 .

19. Barja, P. R.; Tese de Doutorado, Universidade Estadual de Campinas, Brasil, 2000.

20. Taiz, L.; Zeiger, E.; Møller, I. M.; Murphy, A.; Fisiologia e Desenvolvimento Vegetal, $6^{\mathrm{a}}$ ed., Artmed: Porto Alegre, 2017.

21. Matos, E. C. T.; Dissertação de Mestrado, Universidade Estadual do Norte Fluminense Darcy Ribeiro, Brasil. 2013.

22. Almond, D. P.; Patel, P. M.; Photothermal Science and Techniques, Chapman and Hall: London, 1996.

23. Bialkowski, S. E.; Photothermal Spectroscopy Methods for Chemical Analysis, In Chemical Analysis, Winefordner, J. D. ed.; John Wiley \& Sons: New York, 1996, vol. 134.

24. Rosencwaig, A.; Photoacoustics and Photoacoustic Spectroscopy, J. Wiley: New York, 1980.

25. Vargas, H.; Miranda, L. C. M.; Phys. Rep. 1988, 161, 43.

26. Cella, N.; Tese de Doutorado, Universidade Estadual de Campinas, Brasil. 1987.

27. Adams, M. J.; Beadle, B. C.; King, A. A.; Kirkbright, G. F.; Analyst. 1976, 101, 553

28. Perondi, L. F.; Miranda, L. C. M.; J. Appl. Phys. 1987, 62, 2955.

29. Almeida, T. F.; Leite, F. G. H.; Faria Jr., R. T.; Holanda J. N. F.; J. Therm. Anal. and Calorim. 2017, 128, 1265.

30. Leite, F. H. G.; Almeida, T. F.; Faria Jr.; Holanda, J. N. F; Ceram. Int. 2017, 43, 4674.

31. Abritta, T.; Cella, N.; Vargas, H.; Chem. Phys. Lett. 1989, 62, 161.

32. Marquezini, M. V.; Dissertação de Mestrado, Universidade Estadual de Campinas, Brasil, 1990.

33. Barja, P. R.; Dissertação de Mestrado, Universidade Estadual de Campinas, Brasil, 1996.

34. Melo, R. R. de; Filho, J. A. de L.; Rodolfo J. F.; Revista da Sociedade Brasileira de Arborização Urbana 2007, 2, 64.

35. Rousset, G.; Lepoutre, F.; Bertrand, L.; J. Appl. Phys., 1983, 54, 2383.

36. Bults, G.; Horwitz, B. A.; Malkin, S.; Cahen, D.; Biochim. Biophys. Acta 1982, 679, 452

37. Pereira, A. C.; Zerbetto, M.; Silva, G. C.; Vargas, H.; da Silva, W. J.; Neto G. O.; Cella, N.; Miranda, L. C. M.; Meas. Sci. Technol. 1992, 9 , 931.

38. Embrapa. Centro Nacional de Pesquisa de Solos. Manual de Métodos de Análise de Solos. 2a ed. rev. atual.; Embrapa-CNPS: Rio de Janeiro, 1997, ISBN 85-85864-03-6.

39. Silva, R. V.; Dissertação de Mestrado, Universidade Estadual do Norte Fluminense Darcy Ribeiro, Brasil, 2017.

40. Torres, N. A.; Campostrini, E.; Oliveira, J. G; Yamanishi, O. K.; Braz. J. Plant Phys. 2002, 4, 203.

41. Bolletta, A.; Rodríguez, C.; Kruger, H.; Interacciones entre hongos micorrízicos e estrés hídrico: su efecto sobre el rendimiento de trigo. INTA - EEA Bordenave: Buenos Aires, 2002.

42. Silveira, S. V.; Souza, P. V. D.; Koller, O. C.; Pesqui. Agropecu. Bras. 2002, 37, 303 . 
43. Silva, J. G. F.; Ferreira, P. A.; Costa, L. C.; Melendes, R. R. V.; Cecom, P. R.; Rev. Bras. Frutic. 2001, 23, 597.

44. Cruz, J. L.; Coelho, E. F. C.; Pelacani, C. R.; Filho, M. A. C. F.; Bragantia 2004, 63, 351.

45. Cruz, J. L.; Pelacani, C. R.; Carvalho, J. E. B.; Filho, L. F. S. S.; Queiroz, D. C.; Dias, A. T.; Santos, M. T.; Cienc. Rural 2007, 37, 64.
46. Silveira, A. P. D. In Microbiologia do solo; Cardoso, E. J. B. N.; Tsai, S. M.; Neves, M. C. P. eds.; Sociedade Brasileira de Ciências do Solo: Campinas, 1992, pág. 257.

47. Blankenship, R.; Molecular Mechanisms of Photosynthesis, $2^{\text {nd }}$ ed., John Wiley \& Sons: Inglaterra, 2014, pág. 312.

48. Pietikäinen, J.; Kiikkilä, O.; Fritze, H.; Oikos, 2000, 89, 231. 